\title{
ON THE TURBULENT STRUCTURE OF THE MARINE ATMOSPHERIC BOUNDARY LAYER FROM CBLAST NANTUCKET MEASUREMENTS
}

\author{
C.G. HELMIS ${ }^{1, *}$ \\ Q. WANG ${ }^{2}$ \\ G. KATSOUVAS ${ }^{1}$ \\ Z. GAO \\ C.H. HALIOS ${ }^{1}$ \\ J. A. KALOGIROS ${ }^{3}$ \\ S. WANG ${ }^{4}$ \\ G. SGOUROS ${ }^{1}$ \\ J. EDSON ${ }^{5}$
}

Received: 15/05/06

Accepted: 12/07/06

\author{
${ }^{1}$ Department of Applied Physics, Faculty of Physics \\ University of Athens, Greece \\ ${ }^{2}$ Department of Meteorology, Naval Postgraduate School \\ Monterey, CA, USA \\ ${ }^{3}$ National Observatory of Athens \\ Institute for Environmental Research and Sustainable \\ Development, Athens, Greece \\ ${ }^{4}$ Naval Research Laboratory, Monterey, CA 93943, USA \\ ${ }^{5}$ Woods Hole Oceanographic Institute, MA, USA
}

\begin{abstract}
In this work preliminary results on the characteristics of the turbulent structure of the Marine Atmospheric Boundary Layer (MABL) are presented. Measurements used here were conducted in the framework of the Coupled Boundary Layers Air-Sea Transfer Experiment in Low Wind (CBLAST-Low) project. A number of in situ (fast and slow sensors) and remote sensing (SODAR) instruments were deployed on the coast of Nantucket Island, MA, USA.

Measurements of the mean wind, the variances of the three wind components, the atmospheric stability and the momentum fluxes from the acoustic radar (SODAR) revealed the variation of the depth, the turbulent characteristics, and the stability of the MABL in response to the background flow. More specifically, under light south-southwesterly winds, which correspond to the MABL wind directions, the atmosphere was very stable and low values of turbulence were observed. Under moderate to strong southwesterly flow, less stable and neutral atmospheric conditions appeared and the corresponding turbulent quantities were characterized by higher values. The SODAR measurements, with high temporal and spatial resolution, also indicated large magnitude of momentum fluxes at higher levels, presumably associated with the shear forcing near the developed low-level jet.

The measurements from the in-situ instrumentation confirmed that the MABL typically has small negative momentum and sensible heat fluxes consistent with stable to neutral stratification while strong diurnal variations were typical for the land surface Atmospheric Boundary Layer ( $A B L)$. The developed internal $A B L$ at the experimental site was in general less than $10 \mathrm{~m}$ during the night and could reach $15 \mathrm{~m}$ heights during the day, particularly under low-wind conditions.
\end{abstract}

KEYWORDS: CBLAST-Low, marine atmospheric boundary layer, air-sea interaction, SODAR.

\section{INTRODUCTION}

In the recent years, the study of the MABL has been the topic of main interest for atmospheric physics. The CBLAST-Low project aims at understanding of the air-sea interaction and the coupled atmospheric and oceanic boundary layer dynamics at low wind speeds, where the dynamic processes are driven and/or strongly modulated by thermal forcing (Edson et. al., 2004). The objectives of the project are to obtain direct measurements of vertical fluxes (transfer) of momentum, heat and mass across the coupled boundary layers (CBLs), to map 
the 3-D structure of the CBLs over a range of spatial and temporal scales; to identify the processes that drive the flux and CBL structure, to develop and evaluate parameterizations of the flux-producing processes; and to test the mean and variance budgets for momentum, heat, mass, and kinetic energy. Also mesoscale models, large eddy simulations (LES), and direct numerical simulations (DNS) will provide nowcasts, forecasts, and simulations over similar scales.

As part of the CBLAST-Low experiment, we made extensive ground-based measurements on Nantucket Island (figure 1), MA, USA, between July 22 and August 27, 2003. The main objectives of the measurements were to characterize atmospheric boundary layers in a variety of meteorological conditions, to study the turbulent vertical structure of the MABL, and to evaluate mesoscale models, such as the Navy's operational forecast model, COAMPS ${ }^{T M}$. The measurement site was on the west side of the island, at a distance of $90 \mathrm{~m}$ from the waterfront where the land surface was relatively flat. Since the wind was predominantly south or south westerly, the site was chosen so that we had better chance to measure the marine air (Wang et al., 2004).

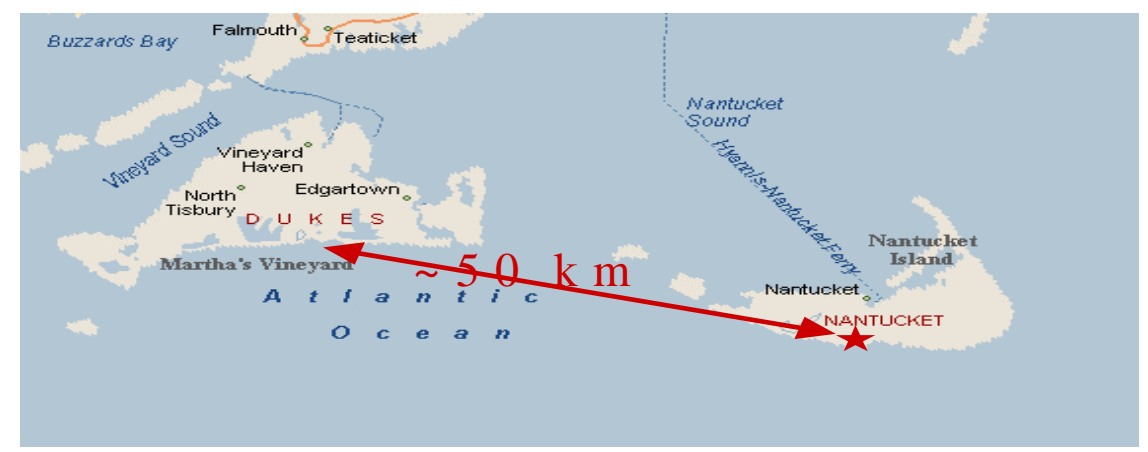

Figure 1. The Nantucket Island

\section{EXPERIMENTAL AREA AND INSTRUMENTATION}

A suite of in situ and remote sensing instruments designed to fully characterize the changing boundary layer properties on the coast of an island was deployed in the CBLAST-Low Nantucket site (figure 2). On a $20 \mathrm{~m}$ meteorological mast, there were two levels (10 and $20 \mathrm{~m}$ ) of high-rate sampling sonic anemometers for 3-D wind components and temperature measurements and a LICOR fast hygrometer at $20 \mathrm{~m}$ for water vapor and $\mathrm{CO}_{2}$ concentration measurements. These high-rate $(2 \mathrm{~Hz})$ measurements yield to the estimation of momentum, sensible heat, latent heat, and $\mathrm{CO}_{2}$ fluxes through the eddy correlation method. There were also measurements of the mean wind, temperature, and relative humidity $(\mathrm{RH})$ at 5,10 , and $20 \mathrm{~m}$ heights at 10 minutes interval, with a sampling frequency of $1 \mathrm{~Hz}$. Soil temperatures at 10 and $30 \mathrm{~cm}$ below the surface and soil volumetric water contents between 10 and $20 \mathrm{~cm}$ below surface were also measured at the bottom of the $20 \mathrm{~m}$ mast. About $10 \mathrm{~m}$ to the north from the $20 \mathrm{~m}$-mast was a $2 \mathrm{~m}$ high mast on a tripod instrumented to measure air temperature, $\mathrm{RH}$, wind speed and direction, air pressure, precipitation, and downward solar radiation at 1minute interval. The Nantucket instrument suite also includes a Remtech (PA2) Acoustic Radar (SODAR) system to measure the vertical profiles of the horizontal wind speed and direction, the vertical $(\mathrm{w})$ and the two horizontal wind components $(\mathrm{u})$ and $(\mathrm{v})$, the standard deviations of the three wind components, the momentum fluxes of the wind components

$\left(\overline{u^{\prime} w^{\prime}}\right.$ and $\left.\overline{v^{\prime} w^{\prime}}\right)$ and the atmospheric static stability. The SODAR measurements were conducted at 30-minute intervals with a vertical resolution of $40 \mathrm{~m}$ and a range up to the height of $800 \mathrm{~m}$. The vertical momentum fluxes, the Turbulent Kinetic Energy (TKE) and the turbulence variances for the three wind components were also calculated. More details regarding SODAR system and it parameters can be found at Helmis et al., 2004. Also a laser ceilometer detected the cloud base height continuously. In addition, rawinsondes were launched twice or four times daily and combined with tethered balloon soundings at the lower $200 \mathrm{~m}$ of the atmosphere contributed to the study of the rapid evolution of the boundary layer thermodynamic structure and particularly the development of the Internal Boundary Layers (IBL). 


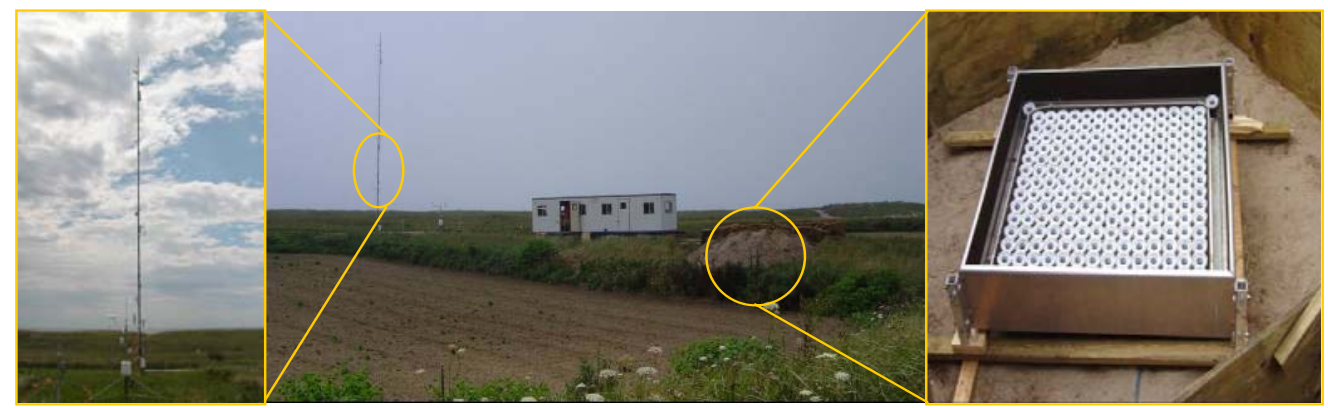

Figure 2. Center: The experimental site. Left: the meteorological mast. Right: the antenna of the sodar system.

\section{THE VERTICAL STRUCTURE OF THE MARINE ATMOSPHERIC BOUNDARY LAYER}

The ability of Acoustic Sounders to measure variances of the wind speed components and turbulent fluxes and to determine turbulence characteristics and scaling parameters is of great interest for $\mathrm{ABL}$ modeling and parameterizations, under different meteorological conditions (Coulter and Kallistratova, 2004). More specifically, using the semi empirical theory of turbulence together with measurements of profiles of mean wind speed and variances of wind components and a simple parameterization, the estimation of TKE and momentum flux profiles is possible, based on SODAR measurements, under near neutral conditions (Kouznetsov et. al., 2004, Kramar and Kouznetsov, 2002).

As an example, preliminary results regarding the MABL structure using data from the SODAR (up to $500 \mathrm{~m}$ height) for the August 19,2003 are presented. The 19th of August is characterized during midnight by weak southerly flow, which after a few hours, changes into strong southwesterly flow. Figure 3 gives the time height cross section of the wind vectors during this day. In the same figure, vectors that correspond to $10 \mathrm{~m}$ height from the mast data are also included. It is evident from this figure that the wind after a short period between 3:30 UTC to 7:30 UTC with weak southerly flow is changing to an intense westerly flow covering a height of $500 \mathrm{~m}$. Conversion from UTC to LST requires a subtraction of 4 hours (LST $=$ UTC $4 \mathrm{hr})$.

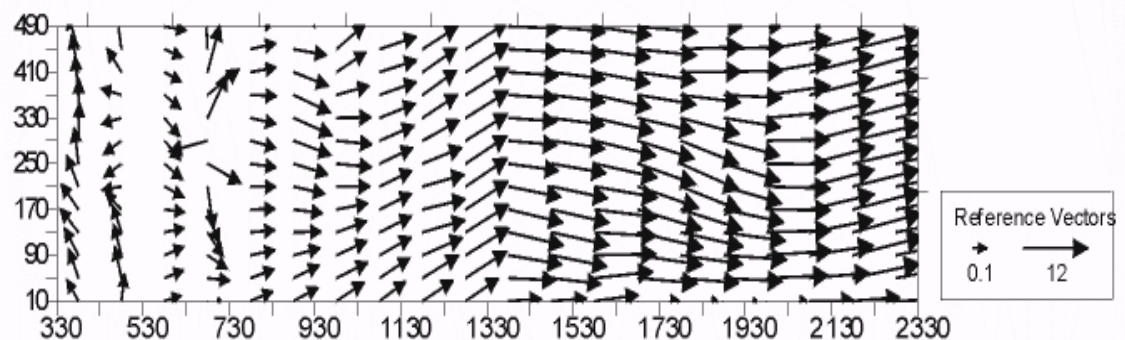

Figure 3. Time-height cross section of the vectors during 19/8/2003. Time is UTC.

The time - height cross section of the wind speed for the same day is given in Figure 4. During the transient period from 5:30 UTC to 7:30 UTC a strong wind shear is evident at higher levels while a well-mixed layer characterized by stronger wind of more than $10 \mathrm{~m} \mathrm{~s}^{-1}$ is present in the afternoon. After 16:00 UTC a Low Level Jet (LLJ) is developed below $200 \mathrm{~m}$.

Figure 5 gives the atmospheric stability class derived from the Sodar for the same day. Stability classes $1,2,3$, and 4 correspond to stable, slightly stable, neutral, and slightly unstable thermal stratifications, respectively. Very stable atmospheric conditions characterize the first hours with southerly flow followed by slight stable to neutral conditions at higher levels. Later on the prevailed intense westerly flow is characterized by a moderate stability. 


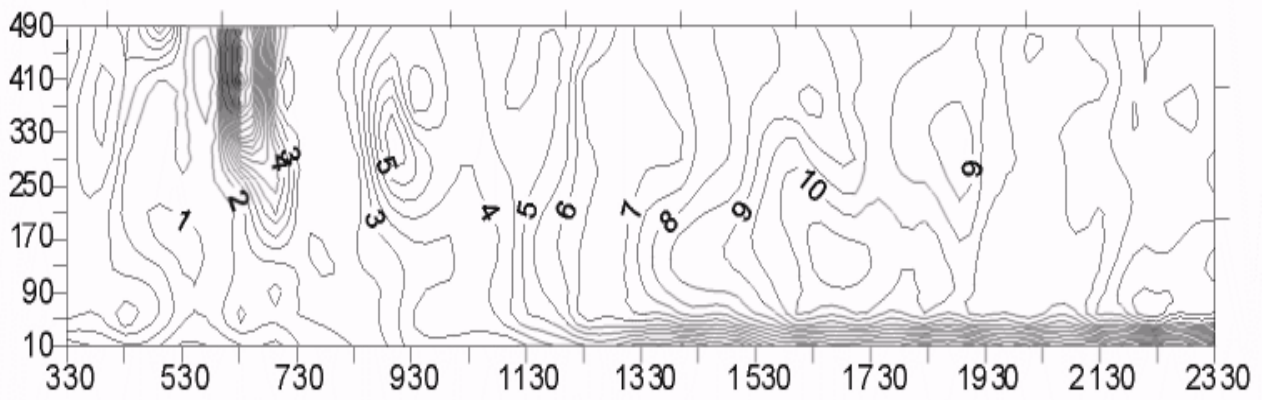

Figure 4. Time-height cross section of the vectors during 19/8/2003. Time is UTC.

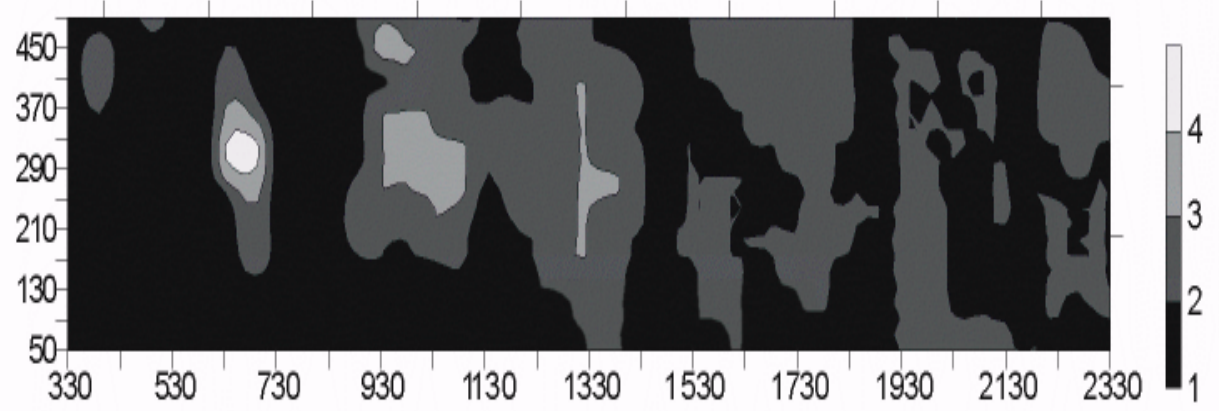

Figure 5. As in figure 4 but for the atmospheric stability. Stability classes explained in text.

The time - height cross section of the standard deviation of the vertical component of the wind speed $\left(\sigma_{w}\right)$ is presented in Figure 6. Very low values of $\sigma_{w}$ are observed during the weak southerly flow and higher values due to the increased turbulence are obtained during the intense westerly flow. Intense turbulence level characterizes the transient period of the wind direction shift.

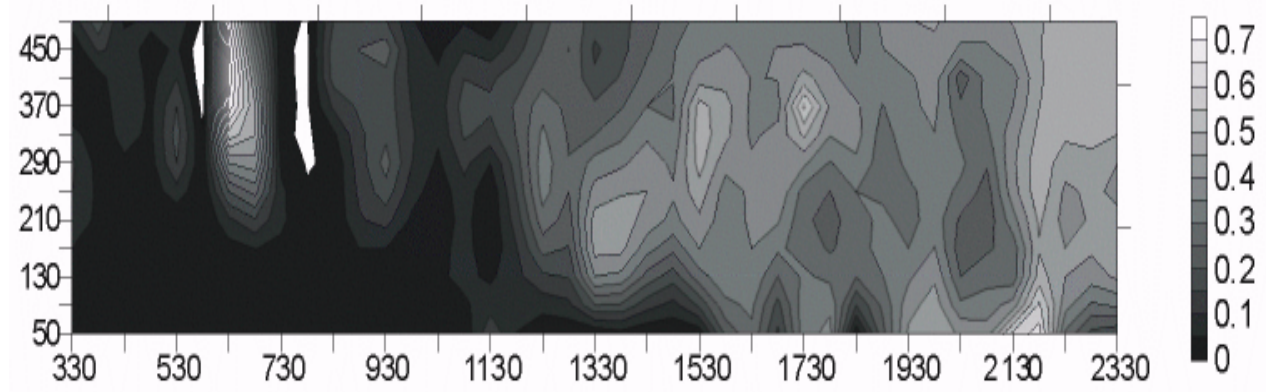

Figure 6. As in figure 5 but for the standard deviation of the vertical component of the wind speed $\left(\mathrm{m} \mathrm{s}^{-1}\right)$

The same characteristics are observed in Figure 7 that gives the magnitude of the momentum fluxes $\left[\left(\overline{u^{\prime} w^{\prime}}\right)^{2}+\left(\overline{v^{\prime} w^{\prime}}\right)^{2}\right]^{1 / 2}$ where intense momentum fluxes are evident at the same periods of time. It's worth mentioning the high values of momentum fluxes observed at heights lower and higher than the LLJ height.

Figure 8 gives the vertical profiles of the momentum fluxes $\overline{u^{\prime} w^{\prime}}$ and $\overline{v^{\prime} w^{\prime}}$, calculated by the Sodar for two different time periods (4:00 and 17:30 UTC). For comparison reasons the values estimated from the $20 \mathrm{~m}$ height sonic anemometer of the mast are also included. From this figure higher values of the momentum fluxes at midday can be observed comparing with the ones observed during midnight. A significant increase of the momentum flux u'w' component is evident below the LLJ height. 


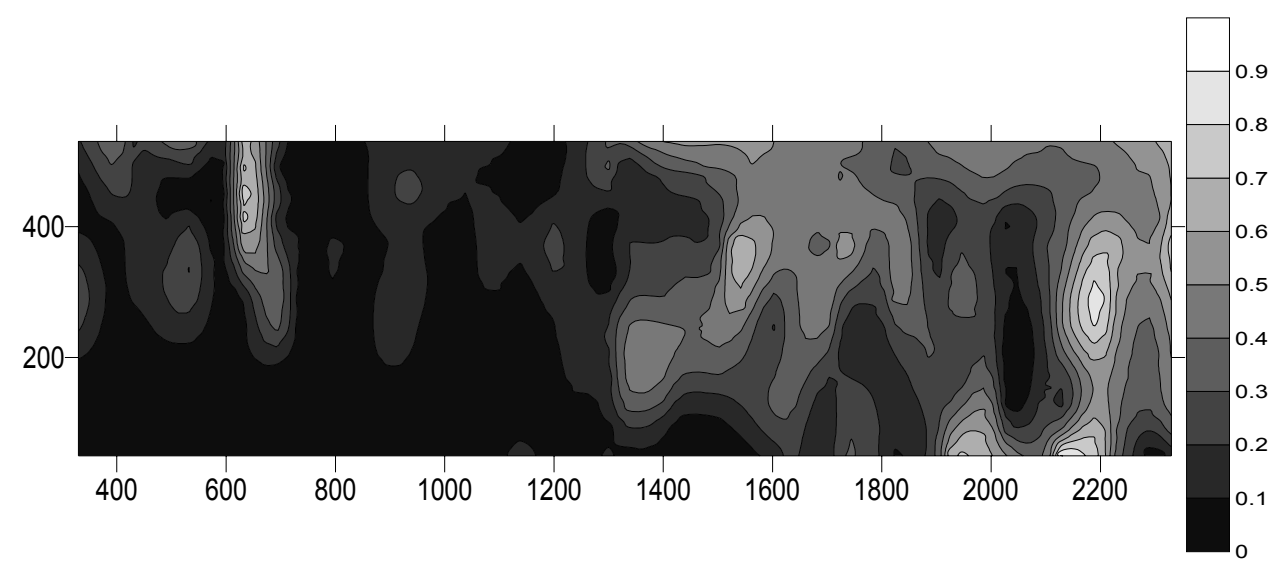

Figure 7. Time height cross-section of the sum of momentum fluxes.

\section{IN SITU MEASUREMENTS IN THE MARINE ATMOSPHERIC BOUNDARY LAYER}

In order to obtain a more complete view of the structure of the MABL, especially of the surface MABL, during August 19, 2003, the time series of the momentum, heat and moisture fluxes, the wind speed and direction, and the stability parameter (-z/L) are presented here. Figure 9 shows the time series of the heat flux $\left(\overline{w^{\prime} T^{\prime}}\right)$ at $10 \mathrm{~m}$ and $20 \mathrm{~m}$ heights, the wind direction at $10 \mathrm{~m}$ height and moisture flux $\left(\overline{w^{\prime} q^{\prime}}\right)$ at $20 \mathrm{~m}$ height. The wind direction gradually changes from eastern sector, during nighttime, when all fluxes are roughly zero, to westerly during the daytime when the heat fluxes reach a maximum at midday. Heat flux at $20 \mathrm{~m}$ height, which corresponds to the MABL, is clearly lower than the respective flux at $10 \mathrm{~m}$ height, which characterizes the developed IBL on the coastline.

Vertical Profiles of ưW - 2003:1904:00, 17:30

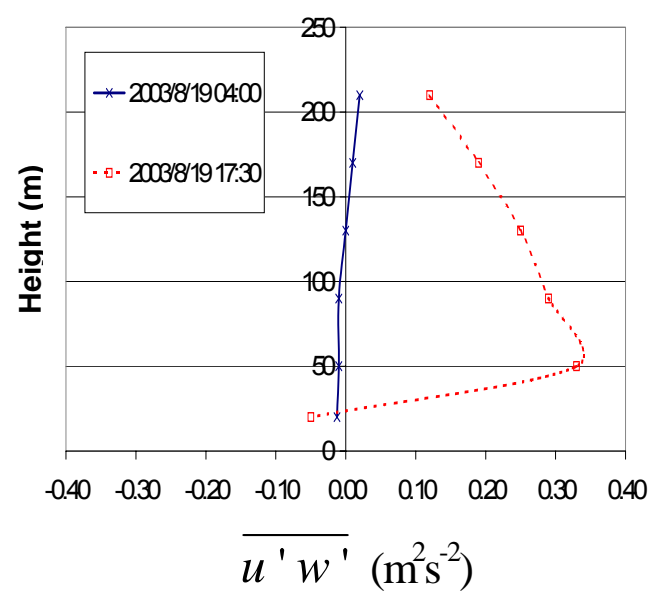

Vertical Profiles of VW 19/8200304:00, 17:30

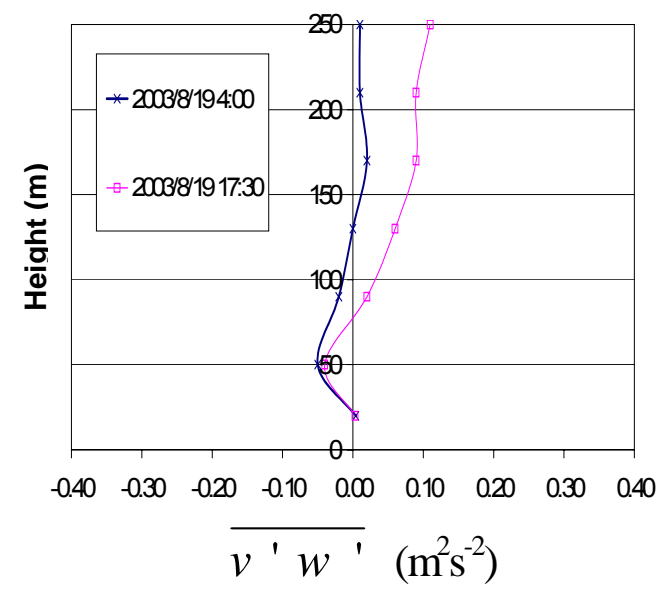

Figure 8. Vertical profiles of the momentum fluxes as derived from the $20 \mathrm{~m}$ sonic anemometer and the Sodar for 4:00,17:30 UTC of August 19, 2003.

Momentum fluxes and temperature (figure 10) seem to follow the same diurnal circle as the heat fluxes. Momentum flux at $20 \mathrm{~m}$ has much lower values during the day than the corresponding one at $10 \mathrm{~m}$ (due to the IBL development). On the other hand, during the night momentum flux at $20 \mathrm{~m}$ is higher than the respective at $10 \mathrm{~m}$ during the time period with easterly flow and both fluxes coincide when the wind direction shifts to westerly flow. It is interesting to note that the difference between temperature at 10 and $20 \mathrm{~m}$ is high during the night and is nearly eliminated during the day (neutral stratification). 


\section{Heat Flux, Moisture Flux and Wind Direction}

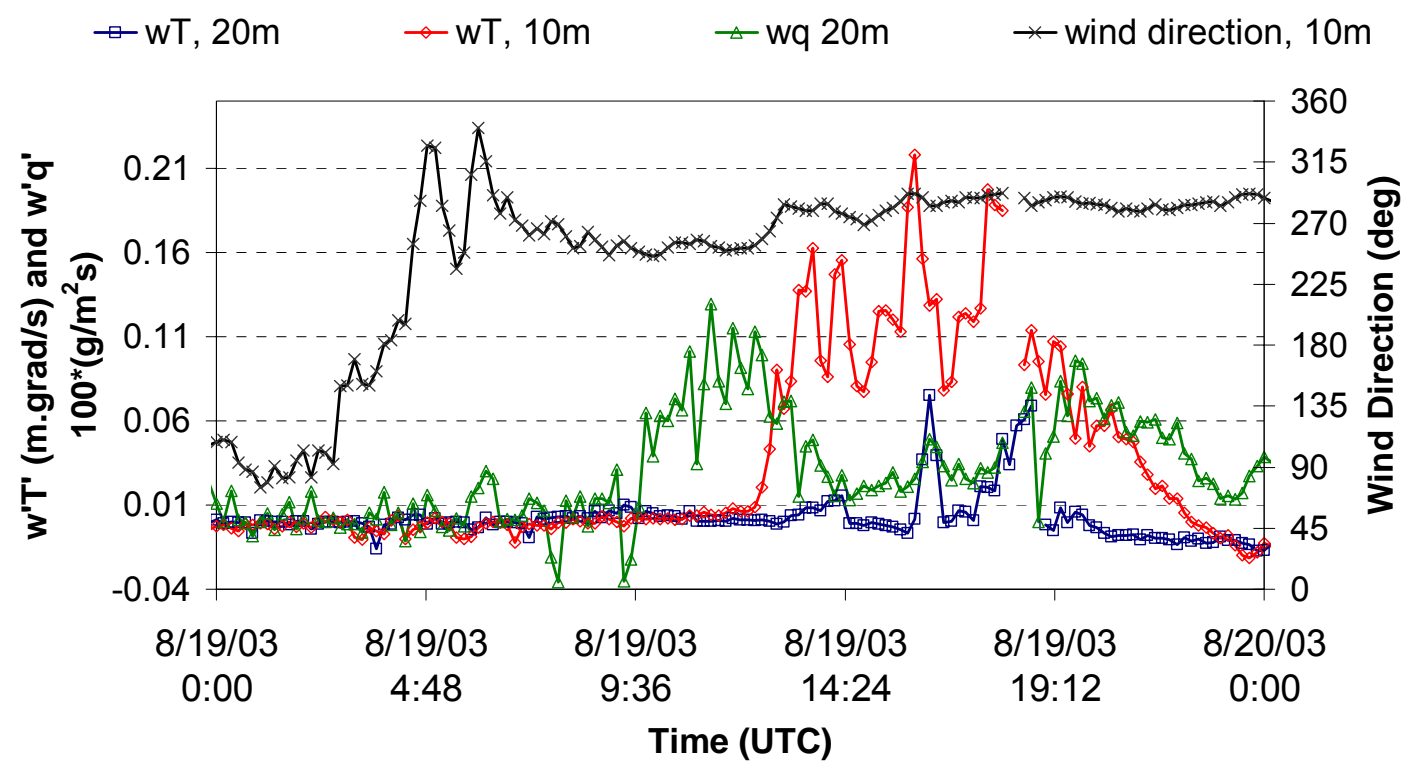

Figure 9. Time series of the heat flux $\left(\overline{w^{\prime} T^{\prime}}\right)$ at 10 and $20 \mathrm{~m}$ height, the wind direction, and moisture flux $\left(\overline{w^{\prime} q^{\prime}}\right)$ at $20 \mathrm{~m}$ height.

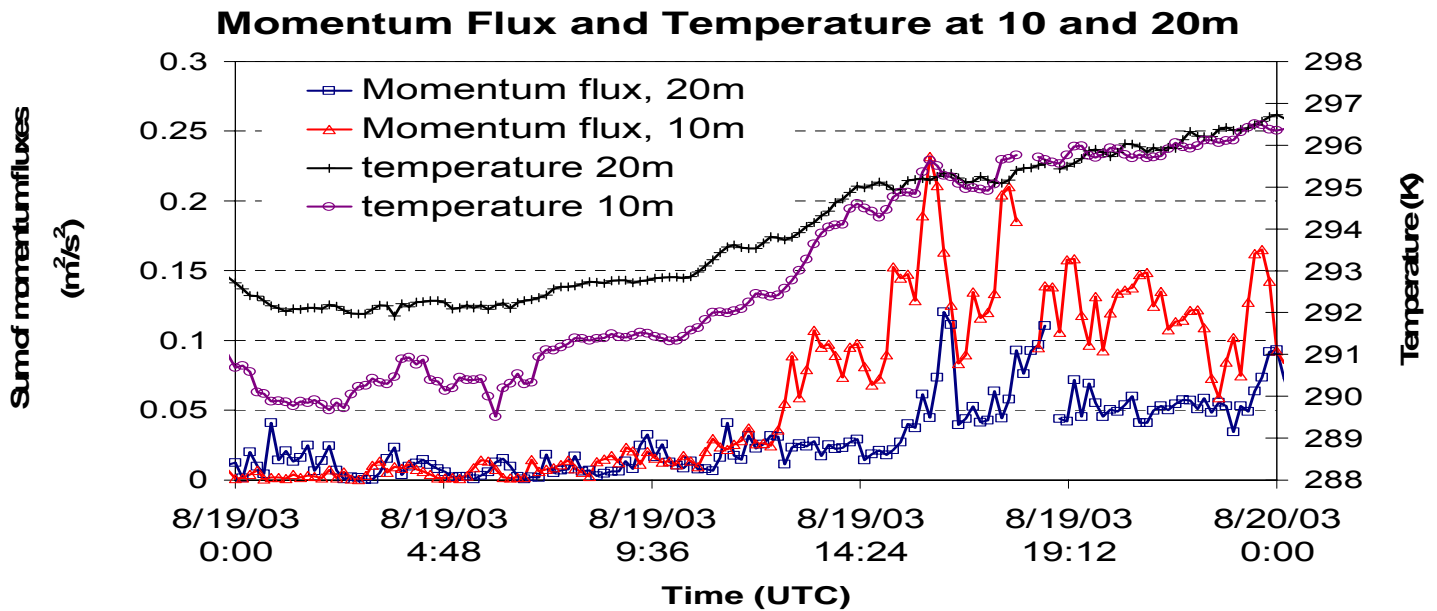

Figure 10. Time series of the sum of momentum fluxes and temperature at 10 and $20 \mathrm{~m}$ height.

The wind speed at both heights is enhanced during the daytime, when neutral atmospheric conditions are established (figure 11). The stability factor exhibits values very close to zero (neutral conditions) under westerly flow (MABL flow) and strong winds. 


\section{Wind Speed and Stability at 10 and $20 \mathrm{~m}$}

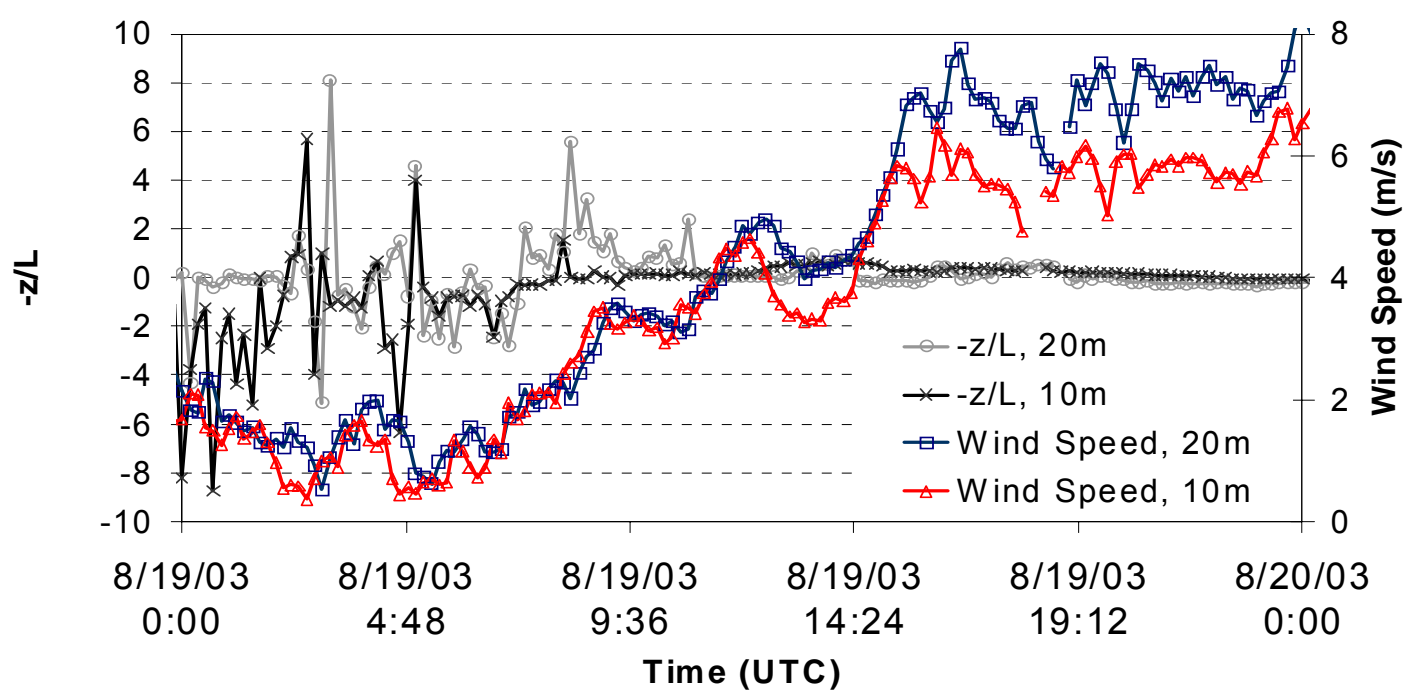

Figure 11 . Time series of the wind speed and the stability parameter $(-z / L)$ at 10 and $20 \mathrm{~m}$ height.

\section{CONCLUSIONS}

The CBLAST-Low experiment, at Nantucket Island, provided a comprehensive data set for air-sea interaction and MABL study. The analysis of measurements related to the mean and turbulent parameters of the MABL, using in situ and remote instrumentation gave a more inside view for the understanding of the MABL vertical structure and the fluxes processes.

According to our findings, under light south-southwesterly winds, which correspond to the MABL, the atmosphere is very stable and weak turbulence is observed. Under moderate to strong southwesterly flow, less stable and neutral atmospheric conditions appear and the corresponding turbulent quantities are characterized by higher values. The SODAR measurements also indicate large magnitude of momentum fluxes at higher levels, presumably associated with the shear forcing near the developed low-level wind maximum. Further study is underway to understand the momentum transport and the TKE balance of the jet-related boundary layer under different meteorological conditions, using more SODAR observations and other relevant measurements from this experiment.

The measurements from the in-situ instrumentation confirm that the MABL typically has small negative momentum and sensible heat fluxes consistent with stable to neutral stratification, while strong diurnal variations are typical for the land $A B L$. In general, the developed internal $A B L$ at the experimental site has a depth of less than $10 \mathrm{~m}$, during the night, but can exceed $15 \mathrm{~m}$ during the day, particularly under low-wind conditions.

\section{ACKNOWLEDGEMENTS}

This work was co-financed within Op. Education by the ESF (European Social Fund) and National Resources and the Office of Naval Research (ONR).

\section{REFERENCES}

1. Coulter, R.L., and Kallistratova, M.A., 2004: Two decades of progress in SODAR techniques: a review of 11 ISARS Proceedings. Meteorol. Atmos. Phys., 85(1-3), 3-20

2. Edson J., Crofoot R., McGillis W., Zappa C., 2004: Investigations of flux-profile relationships in the marine atmospheric surface layer during CBLAST. $16^{\text {th }}$ Symposium on Boundary Layers and Turbulence, 9-14 August 2004, Portland, ME. 
3. Helmis C.G., Wang, Q., Halios C.H., Wang, S. and Sgouros G., 2004: On the vertical turbulent structure of the marine atmospheric boundary layer. $16^{\text {th }}$ Symposium on Boundary Layers and Turbulence, 9-14 August 2004, Portland, ME.

4. Kouznetsov, R.D., Kramar, V.F., Beyrich, E., Engelbart, D., 2004: SODAR-based estimation of TKE and momentum flux profiles in the atmospheric boundary layer: Test of a parameterization model. Meteorol. Atmos. Phys., 85, 93-99.

5. Kramar, V.F., and Kouznetsov, R.D., 2002: A new concept for estimation of turbulent parameter profiles in the ABL Using SODAR data. J. Atmos.Ocean. Tech., 19, 1216-1224.

6. Wang, Q., Helmis, C.G., Gao, Z., Kalogiros, J. and Wang, S., 2004: Variations of boundary layer mean and turbulence structure using synthesized observations. $16^{\text {th }}$ Symposium on Boundary Layers and Turbulence, 9-14 August 2004, Portland, ME. 